\title{
Factors related to healthy sexuality among a group of secondary school students in Galle, Sri Lanka
}

\author{
Patabendige M, Lambiyas PM, Liyanagama N, Medawala M, Liyanage SI, Karunathilaka MMTM, \\ Kularathna KADLR \\ Medical Students of $29^{\text {th }}$ Batch (2005/2006), Faculty of Medicine, University of Ruhuna, Galle, Sri Lanka
}

Correspondence: Dr. Malitha Patabendige (mpatabendige@gmail.com)

\begin{abstract}
Introduction: Sexuality is an important aspect in adolescent health. Safe sexual and social relationships, high self-esteem, concern on body image and knowledge about preventing unwanted pregnancies as well as sexually transmitted infections are essential components of healthy sexuality.

Objectives: To study the level of knowledge and factors related to healthy sexuality among secondary school students in Galle, Sri Lanka.

Methods: A cross sectional study was conducted from May to July 2010 using a sample of 302 secondary school students from 03 selected schools in Galle Municipality area. Those were one boys' school, one girls' school and one mixed school consisting of students from all 04 subject streams recommended for G.C.E. Advanced Level. They were given a self-administered semi-structured questionnaire. Knowledge regarding healthy sexuality was assessed using 20 questions.

Results: In boys 89/141 (63.1\%) and in girls 70/161 (43.5\%) had satisfactory knowledge regarding healthy sexuality. Knowledge was better in boys $(\mathrm{p}=0.001)$ compared to girls, also in boys' school $(\mathrm{p}=0.005)$ compared to other schools and in Bio-science stream $(\mathrm{p}=0.02)$ compared to other streams. Common sources of knowledge were teachers, curriculum and special awareness programmes.

Conclusions: Knowledge regarding healthy sexuality is relatively poor in girls. Actions should be taken to improve the sexual health knowledge among secondary school students in general, giving more emphasis on girls.
\end{abstract}

Keywords: Adolescent health, Students, Sexuality, Knowledge, Sri Lanka

\section{Introduction}

The way people feel about themselves as men or women (self-esteem), the way they feel about their bodies and the way they use them (body image), social roles and relationships related to these can be described as main aspects of healthy sexuality (1). Sexual health means the integration of physical, emotional, intellectual and social aspects of sexuality that positively enriches personality, communication and love (1). The dramatic physical changes of adolescents can be warning to some teenagers especially to those who are shy and who don't ask questions (2). Adolescents are the most vulnerable group for the sexual health problems. Therefore early identification of factors related to healthy sexuality among adolescents is important because such information would facilitate to take necessary strategies and to prevent the negative consequences of lack of knowledge regarding sexual health.

Sexual health of an individual is determined by multifactorial influences including biological determinants, educational contribution, socioeconomic influences as well as cultural and religious 
backgrounds (1). Social influences such as from family members, peer groups, relatives and neighbours are also important factors determining the attitudes of an individual on sexuality.

The consequences of lack of knowledge on healthy sexuality can manifest as increasing incidence of sexually transmitted infections (STIs) including HIV/AIDS, unwanted pregnancies, disturbed family and social education and social stigmatization (4). It's estimated that nearly half of 19 million new STIs in each year are among adolescents aged 1524 years (5). WHO studies reflect that 910,000 conceptions and 356,000 STIs take place daily throughout the world (3). $50 \%$ of these conceptions are unplanned while about $25 \%$ are definitely unwanted (3). The necessity arises in suggesting new strategies to plan sexual education programs in schools, as well as altering ones behaviour in order to achieve an optimally healthy sexual life.

Study objectives were to assess the level of knowledge regarding healthy sexuality and to study the factors related to a healthier sexuality among advanced level students in Galle, Sri Lanka.

\section{Methods}

A descriptive cross-sectional study was conducted in May to July 2010 using a convenient sample of 302 Advanced Level students from 03 selected secondary schools in Galle Municipality area, Sri Lanka. Students were selected from three selected secondary schools consisting of one boys' school, one girls' school and one mixed school. Students from each school were recruited from all four subject streams in Advanced Level curriculum including Bio-science, Mathematics, Commerce and Arts.

A pre-tested, self-administered, semi-structured questionnaire was used. It was developed in Sinhala language according to the research objectives and using references (1). Face validation was done for the questionnaire. The variables studied included knowledge regarding healthy sexuality, age, sex, school type (boys', girls' and mixed) and subject stream. Data collection was done after getting the informed written consent. First section covered socio-demographic characteristics of study participants such as gender, subject stream, religion, monthly family income etc. Knowledge regarding healthy sexuality was assessed using 20 questions.
Those were mainly focused on areas such as, "keeping good relationships with friends in both sexes", "concern on health or shape of the body", "knowledge on genitals and related diseases", "coping successfully with sex related challenges", "delaying sexual intercourse until marriage", "ability in opposing in a sexual harassment", "consulting a trustworthy adult when a sexual problem arises", "avoidance of sexual harassment to others" and possible consequences of lack of knowledge regarding healthy sexuality. One point was given for each correct answer leading to a total of 20 marks. Students who scored 10 or below were categorized as having unsatisfactory level of knowledge and 11-20 points were categorized as having satisfactory level knowledge regarding healthy sexuality. Common sources of information on sexual health and interaction with opposite sex peers were also assessed. Data were analysed using standard statistical methods. Pearson's Chi-square test was performed for significance testing among categorical data. Descriptive statistics was used to summarize the data. $\mathrm{P}<0.05$ was considered as statistically significant.

Data collection was carried out with the permission of school administration. Ethical approval was obtained from Ethical Review Committee, Faculty of Medicine, University of Ruhuna, Galle.

\section{Results}

Total number of 302 students was surveyed from all three selected schools. The demographic characteristics of study population have shown in Table 1.

There is a significant difference $(\mathrm{P}<0.05)$ between knowledge regarding healthy sexuality and gender, school type as well as subject stream respectively. Out of total 141 of boys, 89 (63.1\%) and out of total 161 of girls, 70 (43.5\%) had satisfactory knowledge regarding healthy sexuality. Knowledge was better in boys $(\mathrm{P}=0.001)$ compared to girls. Sixty three students out of $99(63.6 \%)$ in boys' school, and 51 students out of $100(51 \%)$ in mixed school, as well as 42 students out of $103(41 \%)$ in Girls' school, respectively showed a satisfactory level of knowledge. Therefore, students in boys' school have a better level of knowledge compared to other two schools $(\mathrm{P}=0.005)$. Knowledge regarding healthy 
sexuality was better among students in Bioscience stream (53 out of 82 which is $64.6 \%$ ) compared to those who study in Mathematics (38 out of 75 which is $50.6 \%$ ), Commerce (30 out of 75 which is $40 \%$ ) and Arts (37 out of 70 which is $52.8 \%$ ) respectively. It was significant with a $\mathrm{P}=0.02$. Possible consequences of lack of knowledge regarding healthy sexuality have summarized in Table 2.

Majority of male students which is 84 out of 141 , $(59.6 \%)$ tend to discuss their sex-related issues with their friends, while majority of female students which is 107 out of $161,(66.5 \%)$ tend to discuss such issues with their mothers. Generally within the school background, most available sources of the knowledge regarding healthy sexuality are teachers and school curriculum. Special awareness programmes are second commonest source. It was obvious that the usage of library materials was comparatively low as a source.

When sources outside the school are considered, explicit videos were a frequently contacted one. They gain access to these via internet, mobile phones or DVDs circulating among them. Out of 141 boys, $107(75.8 \%)$ have watched an explicit scenes using DVDs at least once in their lifetime and only 9 out of 161 girls (5.6\%) have had this experience. Use of mobile phones for explicit material was 105 out of $141(74.5 \%)$ boys and 2 out of $161(1.2 \%)$ girls.
Majority of students believed that love affairs are not acceptable and they interfere with studies. However, a significant percentage of boys (14\%) were also in the idea that love affairs support their studies and they create a reputation among friends.

\section{Table 1: Characteristics of study participants}

\begin{tabular}{lc}
\hline Number of participants $(\mathbf{n}=\mathbf{3 0 2})$ \\
\hline Gender & \\
Male students & $141(46.7 \%)$ \\
Female students & $161(53.3 \%)$ \\
\hline Subject stream & \\
Bioscience & $82(27.2 \%)$ \\
Mathematics & $75(24.9 \%)$ \\
Commerce & $75(24.9 \%)$ \\
Arts & $70(23.2 \%)$ \\
\hline Religion & \\
Buddhist & $204(97.4 \%)$ \\
Islamic & $6(2 \%)$ \\
Catholic & $2(0.6 \%)$ \\
\hline
\end{tabular}

Monthly family income

$\begin{array}{ll}<\text { Rs. } 10,000 & 115(38 \%) \\ \text { Rs. } 10,000-\text { Rs. } 20,000 & 106(35 \%) \\ >\text { Rs. } 20,000 & 81(27 \%)\end{array}$

Table 2: Possible consequences of lack of knowledge regarding healthy sexuality

\begin{tabular}{|l|l|l|}
\hline $\begin{array}{l}\text { "Possible consequences of lack of } \\
\text { knowledge regarding healthy } \\
\text { sexuality......" }\end{array}$ & $\begin{array}{l}\text { Correctly } \\
\text { answered male } \\
\text { students }\end{array}$ & $\begin{array}{l}\text { Correctly } \\
\text { answered } \\
\text { female students }\end{array}$ \\
\hline 1. Teenage pregnancies & $110(78.0 \%)$ & $125(77.6 \%)$ \\
\hline $\begin{array}{l}\text { 2. } \\
\text { unrest }\end{array}$ & $100(70.9 \%)$ & $105(65.2 \%)$ \\
\hline $\begin{array}{l}\text { 3. Inability to cope successfully } \\
\text { with sex related challenges }\end{array}$ & $71(50.4 \%)$ & $86(53.4 \%)$ \\
\hline $\begin{array}{l}\text { 4. Risk of contracting sexually } \\
\text { transmitted infections }\end{array}$ & $114(80.9 \%)$ & $116(72.0 \%)$ \\
\hline $\begin{array}{l}\text { 5. Inability to keep good } \\
\text { relationships with peers }\end{array}$ & $85(60.3 \%)$ & $56(34.8 \%)$ \\
\hline $\begin{array}{l}\text { 6. Inability to maintain a good } \\
\text { married life }\end{array}$ & $94(66.7 \%)$ & $107(66.5 \%)$ \\
\hline
\end{tabular}




\section{Discussion}

According to results of our study, male students have a better knowledge on healthy sexuality compared to that of females. A study done in Tanzania has reported that female students are more vulnerable to STIs compared to male secondary schools students (6). In the mixed school, boys and girls have an average level of knowledge on healthy sexuality. However it was lower in girls' school than in boys' school. Knowledge regarding healthy sexuality seems to vary with the subject stream and relatively poor among commerce and arts students. Majority of male students tend to discuss their sex related problems with a friend. Study done in Malaysia has shown to improve the effectiveness of a peer-led education program related to HIV/AIDS among university students (7). But they emphasize that it may take a longer time for behavioral changes to occur (7). Most of the girls tend to discuss their issues with their mother. A study done among female school students in Saudi Arabia shows that only 15.8\% discussed sex related issues with their mothers and $61 \%$ had reported that their school teachers showed negative attitudes toward questions related to sexual issues (8). Furthermore, it's suggested that formal sexual education is worthwhile to be included to school curriculum within the context of cultural and religious background of a particular country (8). At the same time, parents and teachers have to be more open minded to discuss sex related matters with their children and students (8). Mass media also has shown to be an effective way of educating the secondary school students on STIs in Tanzania (6). Galle is the main city in the Southern Province of Sri Lanka. Socio-economic status in most of the provinces is lower than that of Southern Province in Sri Lanka (9). Therefore, we cannot expect satisfactory results for knowledge regarding healthy sexuality generally from Sri Lankan secondary school students.

This study was conducted in a limited setting and sampling wasn't done randomly. Therefore, this may not be adequately representative. There was a difficulty in gathering information regarding the topic due to lack of studies done in Sri Lanka on this field. Since we had to conduct the data collection during school hours, the time factor might have affected the responses of the students. Besides the effects of social and cultural barriers, students might not have given the genuine answers. The study was conducted in three urban schools. There is a possibility of getting different results if a rural set up was subjected to the particular study. However other relevant aspects of adolescent sexual health such as sexual practices and contraceptive usage were not assessed in this study. If some questions about sexual practices would have been asked, it might have given some additional information improving the outcomes of study. Our questionnaire also was not properly validated to Sri Lankan setting. Those are the limitations of this study.

It can be concluded that knowledge regarding healthy sexuality is still not satisfactory and it's relatively poor especially among girls. Cultural barriers seem to play a significant influence on expressing their attitudes regarding sexuality, especially for girls. Actions should be taken to improve the sexual health knowledge of advanced level students in general, giving more emphasis towards girls.

It can strongly be recommended that conducting special awareness programmes, improvement of library facilities and educational materials on healthy sexuality in schools as necessary strategies. More attention should be given to the mathematics, arts and commerce students to improve their knowledge through school curriculum. Special programmes can be held for the parents, especially to mothers of girls on how to educate their daughters regarding healthy sexuality. Implementation of a counseling department in schools also seems to be worthwhile.

\section{Acknowledgements}

Authors express their sincere gratitude to Dr. Bilesha Perera, Head / Department of Community Medicine, Faculty of Medicine, University of Ruhuna, Galle for his invaluable guidance and to all the students who participated in the study.

\section{Conflicts of interest}

No conflicts of interests. 


\section{References}

1. International Federation of Red Cross and Red Crescent Societies. An introduction to sexual health, 1995.Geneva: International Federation of Red Cross and Red Crescent Societies 1995.

2. Bancroft J, Biological factors in human sexuality; Journal of Sex Research 2002 Feb; 39(1): 15-21.

3. World Health Organization. Reproductive health - A key to brighter future. Biennial report 1990-1991. Geneva: World Health Organization 1991.

4. Bott S, Jejeebhoy S, Shah I, Puri C, editors. Towards Adulthood: Exploring the Sexual and Reproductive Health of Adolescents in South Asia. Geneva: World Health Organization 2003.

5. Weinstock H, Berman S, Cates W. Sexually transmitted diseases among American youth: incidence and prevalence estimates, 2000. Perspectives on Sexual and Reproductive Health 2004; 36(1): 6-10.
6. Mwambete KD, Mtaturu Z. Knowledge of sexually transmitted diseases among secondary school students in Dar es Salaam, Tanzania. African Health Sciences 2006 Sep; 6(3): 165-9.

7. Ibrahim N, Rampal L, Jamil Z, Zain AM. Effectiveness of peer-led education on knowledge, attitude and risk behavior practices related to HIV among students at a Malaysian public university - A randomized controlled trial. Preventive Medicine 2012 Sep 11.

8. Alquaiz AM, Almuneef MA, Minhas HR. Knowledge, attitudes, and resources of sex education among female adolescents in public and private schools in Central Saudi Arabia. Saudi Medical Journal. 2012 Sep; 33(9):1001-9.

9. Department of Census and Statistics 2007, Sri Lanka. http://www.statistics.gov.lk/HIES/HIES2006_07Website /Publications/HIES200607Final\%20ReportWeb\%20.pdf [Accessed in 14 October 2012] 